\title{
Environmental Considerations About the Life Cycle of Biofuels
}

\author{
Estelvina Rodríguez Portillo, \\ José Ricardo Duarte Ojeda and \\ Sully Ojeda de Duarte \\ Additional information is available at the end of the chapter
}

http://dx.doi.org/10.5772/52481

\section{Introduction}

Environmental concerns, along with the goals of energy diversification and rural development, accompanied by policies that drive the use of liquid biofuels for transport in several countries, notably in Europe. Since they started these policies, the perception of the environmental benefits of biofuels has changed significantly. At present there is controversy regarding the benefits and possible negative consequences in terms of environmental impact.

The questions are given based on two negative consequences directly: the occupation of natural areas to expand cultivation and, on the other side, energy efficiency in addition to the possible influence on food prices. The latter reinforces the transformation of natural areas to agricultural land.

This chapter discusses environmental considerations in the life cycle of one of the most widely used biofuel today, the biodiesel obtained from sunflower oil. The environmental impacts along the life cycle approach are described and quantified as well, based on the structure proposed by the ISO: 14040, results of empirical research, conducted in the southern part of eastern Paraguay. To do this, we performed field inventory and assessment of impact by weighting and standardization, supported by LCD SIMAPRO 7.0 program. By unifying features protection areas, evaluations were obtained by assigning a weight range of $40 \%$ importance to human health, $40 \%$ for ecosystem quality and $20 \%$ for resources. Topics to be covered in this chapter include descriptions of the agricultural phase, production of sunflower oil and the industrial stage of biodiesel production. Finally, the proposed units in each category were assessed according to the characterization factors and corresponding 
formulae and graphs were generated impacts in relation to the three protected areas: damage to human health, ecosystem quality and resources, being this the identification of potential impacts.

\section{Life cycle assessment}

ISO: 14040, 97 defines Life Cycle Assessment (LCA) as "the collection and evaluation of the inputs and outputs and potential environmental impacts of product system throughout its life cycle. "It is a methodology promoted by the United Nations Program for Environment, driven at the World Summit on Sustainable Development in Johannesburg and standardized in the series 14040, within those for ISO 14000 environmental own efforts. This analysis includes four main stages (Figure 1) comprising the definition and scope, inventory analysis, impact assessment and interpretation of results.

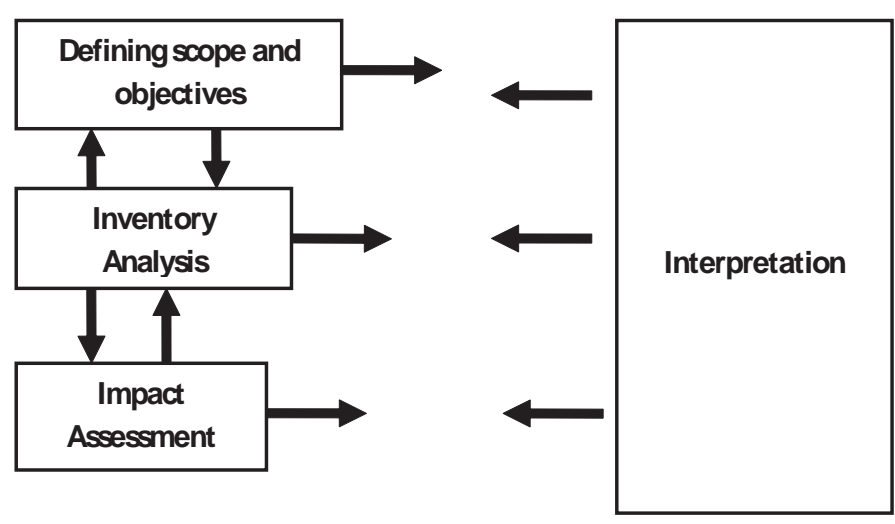

Figure 1. Structure of the life cycle

\subsection{Definition and scope}

This stage of the process/service/activity begins by defining the global benefits of the research, in which the purpose of the research, the product, the potential market, the importance or significance of the research (limitations of the system), the functional unit, the necessary data and the analysis to be carried out are established.

\subsection{Inventory analysis (Life Cycle Inventory LCI)}

The analysis for the life cycle for biodiesel consists of processes and systems connected by their common end: the making of the product. Part of this process is the analysis of the inventory that refers to a quantified list of all the incoming and outgoing flows of the system during its working life, and which are extracted from the environment or produced in it by 
calculating the energy requirements and materials of the system, and the energetic efficiency of its components, as well as the emissions in each of the processes and systems.

\subsection{Impact assessment (Life Cycle Impact Assessment - LCIA)}

An evaluation of the classification and assessment of the inventory is carried out according to the inventory analysis lists, and its results are related to evident environmental effects.

\subsection{Results interpretation}

All results of the preceding part are assessed together in a rational way and according to the previously defined objectives of the research so as to establish conclusions and recommendations for the decisions to be made.

The LCA method is a dynamic one and the four stages in which it is carried out are all connected, as shown in figure 1 . Thus, data may be modified or improved as soon as new results are achieved. Social aspects are not typically taken into account by the LCA and it is therefore necessary to use other techniques which provide us with the social problems panorama on this matter (Rajagopal and Zilberman, 2007).

The inventory or environmental balance was divided into the following subsystems: agricultural phase, industrial phase of the oil and industrial phase of the biodiesel, as well as the different means of transport for distribution and use.

\section{Content of the agricultural phase - Sunflower crop}

This section describes the agricultural process of growing sunflower and quantified inputs and energy expenditure. The raw material is the sunflower species Elianthusannus, short cycle (three months or so) from November to January. The technology used is the double disk tillage (Marchetti et al., 2007).

The flows of energy during the lifespan of biodiesel are divided directly and indirectly. A flow of direct energy corresponds to the energy consumed in the way of fossil fuels; firewood, electricity, water steam, and diesel used in; farming operations such as plowing before sowing, defense, and harvest of the crops (Donato, 2007). Fuel used in the transportation of the harvested grain from the field to the stocking plant, industry and drying, denominated in this case short-haul freight (adding short distance of $30 \mathrm{~km}$ and 150 $\mathrm{km}$ ), according to the Márgenes Agropecuarios, 2009. Fuel used in the process of drying which is carried out in a stocking plant whose objective is the reduction of the humidity percentage of the harvested grain, using firewood and water steam for this effect. Electrical energy used in the industrial process for the process of transesterification and maintenance of buildings, which comes from hydro electrical energy (used in the country). 

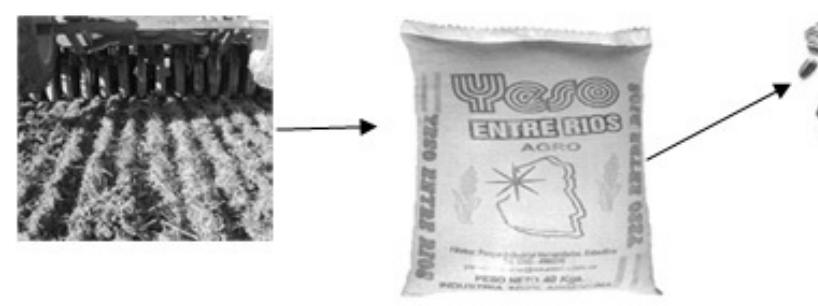

Direct seeding

1 Planting (Double disc)

1 Fertilizing, compost

4 Pesticide application

1 Harvest

Transport (Short freifht- Freight to middle distance)
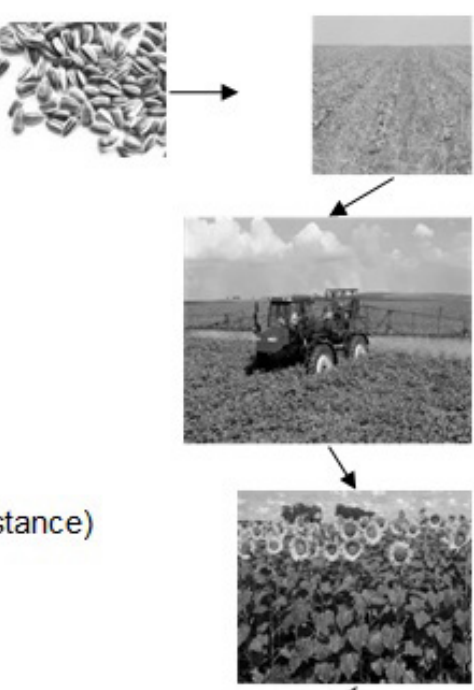

$\checkmark$

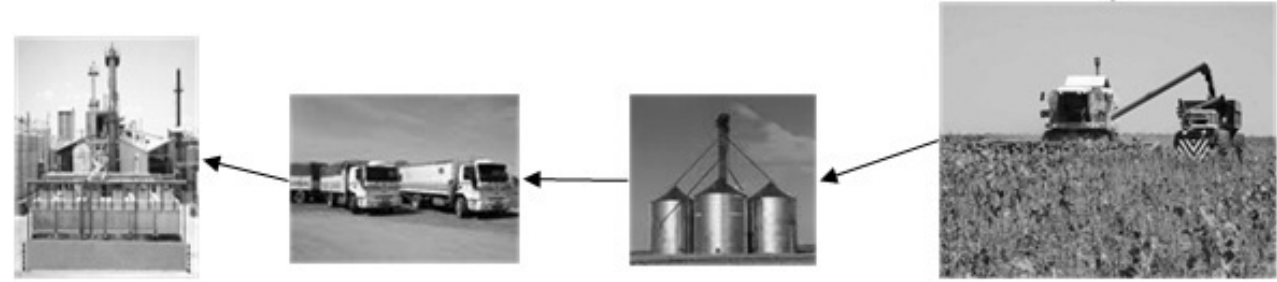

Figure 2. Scheme of the Agricultural Phase Process.

Indirect contributions of energy include the quantities of the agricultural supplies (seeds, fertilizers, and agrochemicals) in order to produce a determined amount of grains per hectare, which is taken as raw material to the process of transformation into biofuels, and the raw materials used in the elaboration of oil and then biodiesel. The outflows of solid, liquid, and gas effluents in each phase, multiplying the amounts by their corresponding energy coefficient. Consistency and balance analysis were carried out to verify the homogeneity of the values (Anderson and Valenzuela, 2007). 

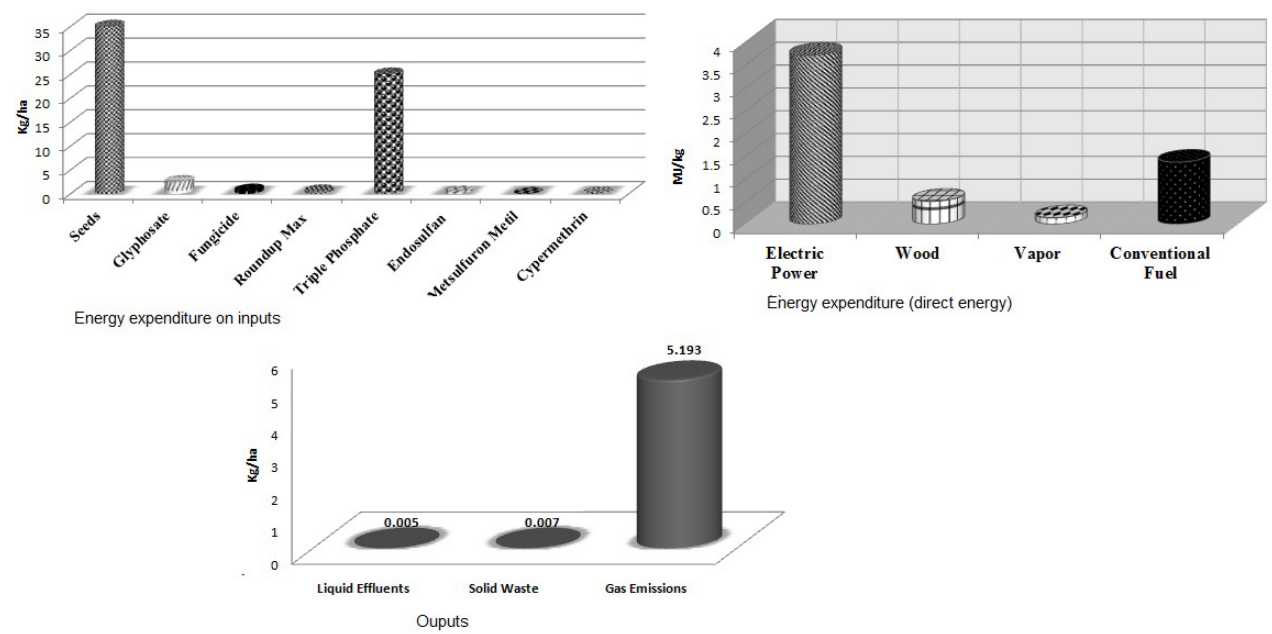

Figure 3. Energy expenditures and outputs.

\section{Sunflower oil collection}

The technology used in developing the oil is a mixed system, mechanical (pressing) and chemical (solvent extraction).It describes the followed process and the main elements involved in input and energy expenditure.

Once sunflower has been harvested, it has to be cleaned, dried and stored under the adequate conditions. During the storing process seed are rolled in cylinder mills to be moistureconditioned. Oil is extracted by pressing, and then solvent extraction is done using hexane. Oil is separated from the solvent by using the distillation of micelle and hexane is eliminated from the flour and this is now dried and toast. Finally, crude oil is extracted; refined and sunflower pellet is processed. 


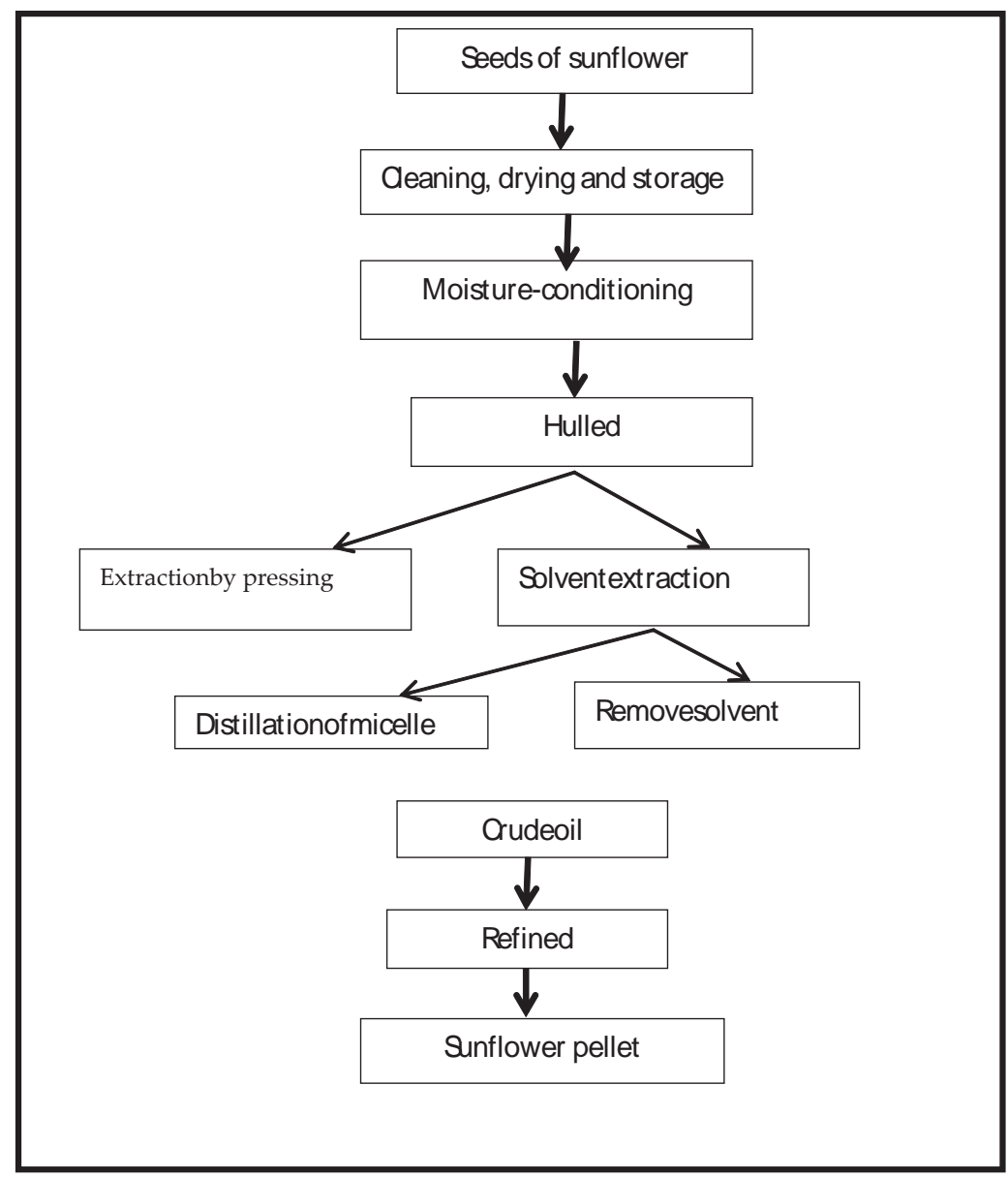

Figure 4. Biodiesel scheme of production. 

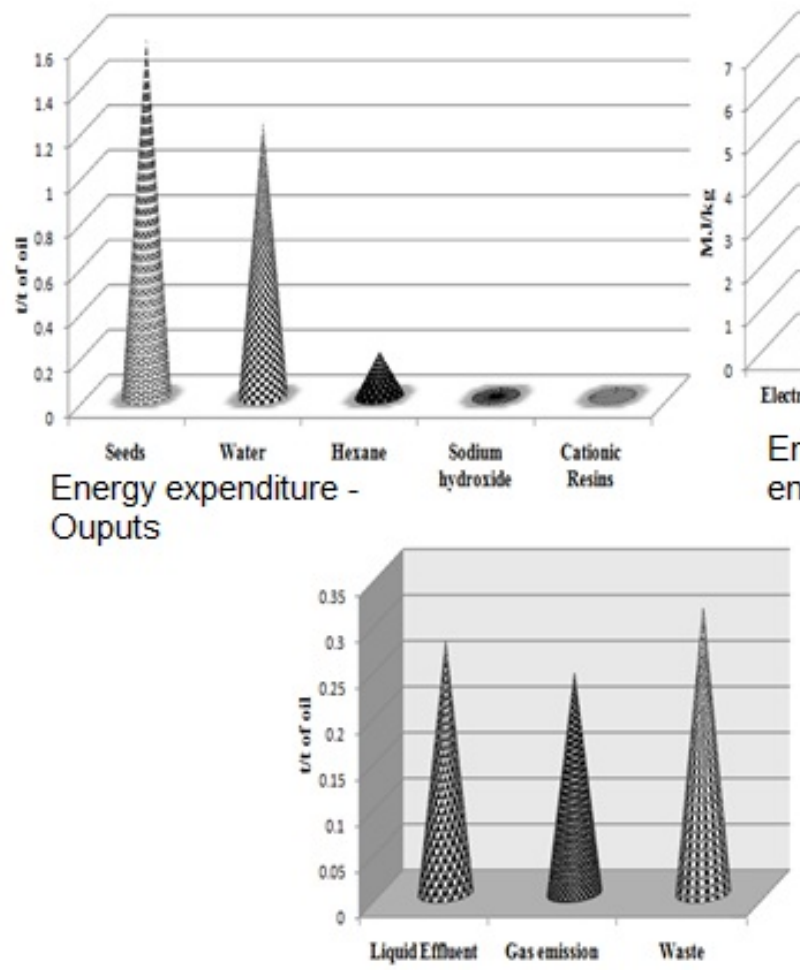

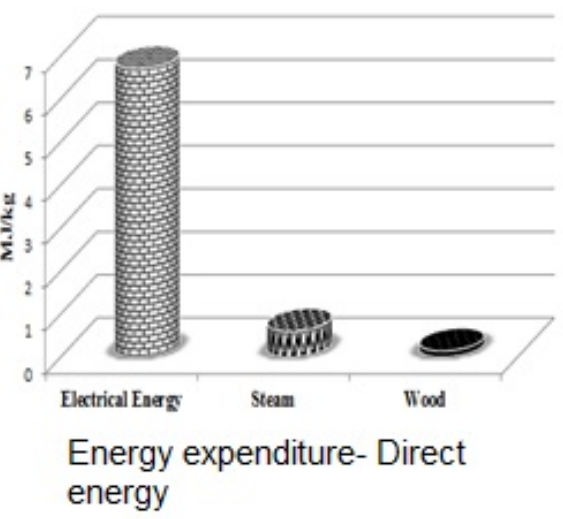

Figure 5. Balance analysis.

\section{Biodiesel production}

The biodiesel is made from sunflower oil transesterification in a continuous system using mainly methanol and potassium hydroxide as a catalyst obtained as major by-product glycerin. This process involves the use of oils or fats containing free acidity, and in its first phase the free fatty acids are also transformed into methyl ester.

Alternative fuel is produced from vegetable oils, turning triglycerides into methyl or etil esters. This is commonly achieved trhough a method known as transesterification, in which reactions from the three acid chains (ester chains) of each triglyceride molecule are produced by an alcohol and, as a result, these chains are separated from the glycerin molecule.

This separation needs temperature and a powerful base catalytic, such as a hydroxide, for the reaction to be complete. Methanol is generally used for this purpose, although many other alcohols, like ethanol, propane or butane, can be used. Glycerin is obtained as a by- 
side product and this can be used in other industrial matters, making it a positive factor from the economic point of view (Ma and Hanna, 1999).
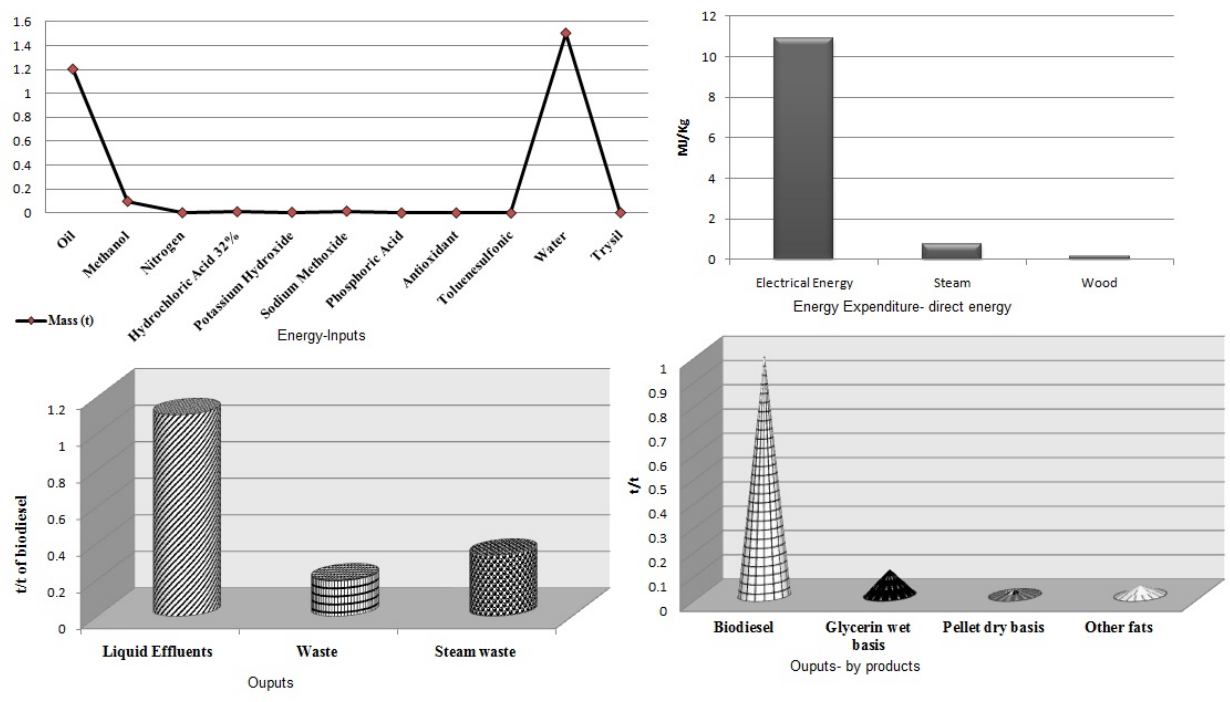

Figure 6. Biodiesel energy balance.

The total of energy consumption for the production of biodiesel was obtained by adding the industrial and farming stages and the different transport of the intermediate products, In figure 6, the total energy expense compared by phases can be observed; in the same figure, it can be observed that the highest direct expense is presented during the stage of industrial transesterification of biodiesel because of the high use of electricity in this phase. However, the largest inflow in supplies and indirect energy expense comes in obtaining the oil because of the higher amount of energy contents in the materials involved in this process. 


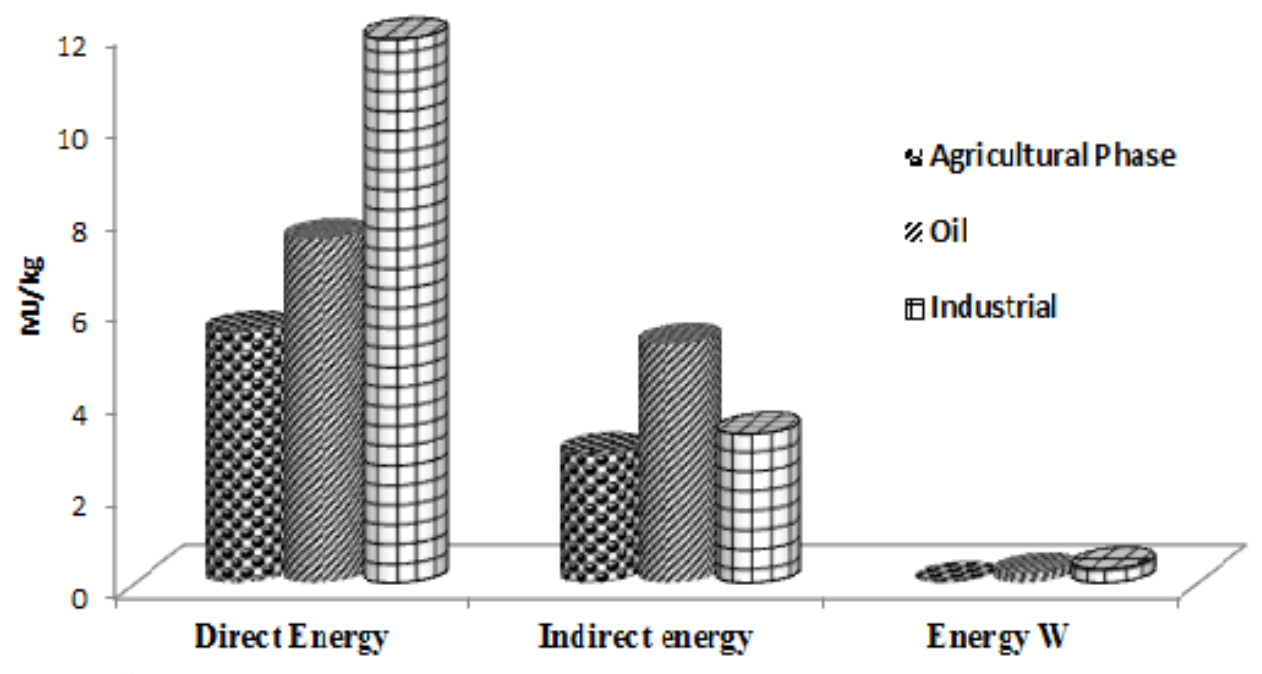

a)

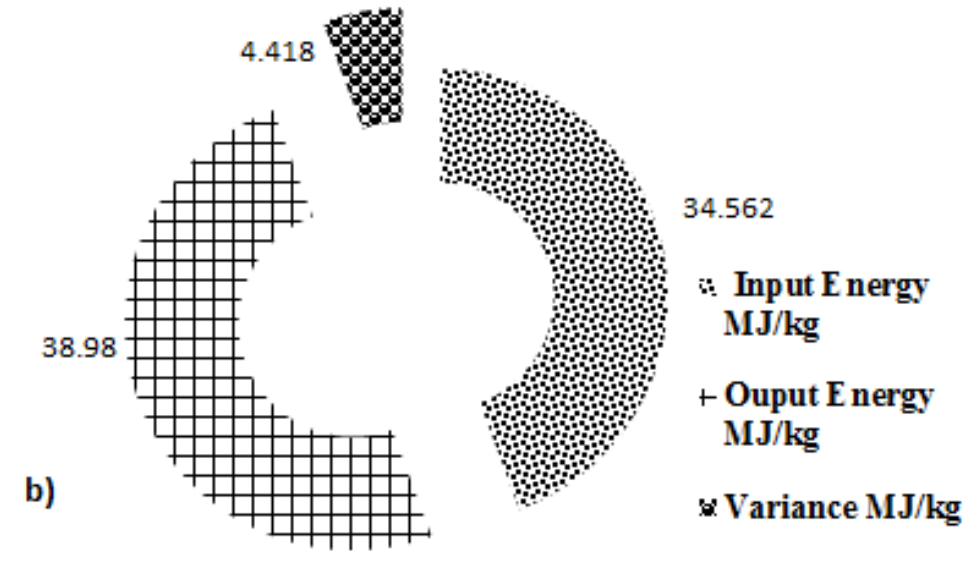

Figure 7. Total energy expense of the cycle, in direct energy consumption, indirect energy, and emission outflow energy, and final energy balance.

\section{Identification of impacts on the life cycle}

This section gives an overview of the environmental impact of the system under study which results indicate that it is strictly linked to the agricultural phase, although the indicators evaluated the impact is minor compared to other countries such as Argentina and the U.S. The use of fossil fuels, pesticides and phosphate fertilizers are important influencing 
factors in the Life Cycle Assessment. There is a need to diversify the raw material, for obtaining biodiesel to avoid overuse of soil and other environmental considerations that are practice-based agricultural monoculture. A biodiesel involvement of second and third generation would therefore be relevant.

\subsection{Environmental burden - Flow of materials}

Environmental impact per mass and energy units. This was determined through the flow of the mass vector, for which the following was taken into account: each flow in the process $\left(\mathrm{Kg}_{\mathrm{g}} \mathrm{s}^{-1}\right)$ is associated to an eco vector $\mathrm{v}$, which elements are expressed in mass ( $\mathrm{Kg}$ of the polluting agent per $\mathrm{Kg}$ of the product) or in energy $\left(\mathrm{Kj} \mathrm{Kg}^{-1}\right)$.

\subsection{Energy balance}

Coefficient of measurable energetic flow that goes in and out of the biodiesel Life Cycle to determine the quantity of renewable energy that is accumulated in each gram of biodiesel per unit of not renewable energy wasted during its life cycle. This was carried out through the Input/output Ratio connection, from the vector flow for energy (Harding et al, 2008)

To assess the impact of the Life Cycle the SIMAPRO LCD software, version 7.0, was used. This is a model of an environmental mechanism which implies three main factors: the geographical characteristics, the elements to be used and the applied technology. An analysis of the inventory was carried out in the field in order to do so, and the following aspects were taken into account:

Energy income: (water steam, electricity, fuels)

Products - by-side products

Raw material income (sunflower seeds, oil, methanol)

Auxiliary income (acids, fertilizers, pesticides, water-soil use)

Waste (urban solids, industrial solids, dangerous solid)

Emissions to water, air and soil (gas, liquid effluents, sunflowers pellet, pesticides containers)

Assignment method: the assignment methods used were the quantification (mass quantity, using scales), the estimation (from the estequiometric connections) and calculation (heating power of the used energy).

The proposed units for each category are valued according to the description factors and the corresponding formulae, and impact graphics of the three protection areas pointed out by ISO 14040 were generated: human health damages, resources and ecosystem quality. The description enhances the analysis of the impact of biodiesel upon the affected environmental factors through descriptive factors for each component. Categories such as Never: with factor $=0$ with results $=0$ are omitted. 
The next graph shows all the effect categories. Since these are expressed in different units, they are shown in a percentage scale. They indicate the relative contribution for each phase of the product (11 phases).

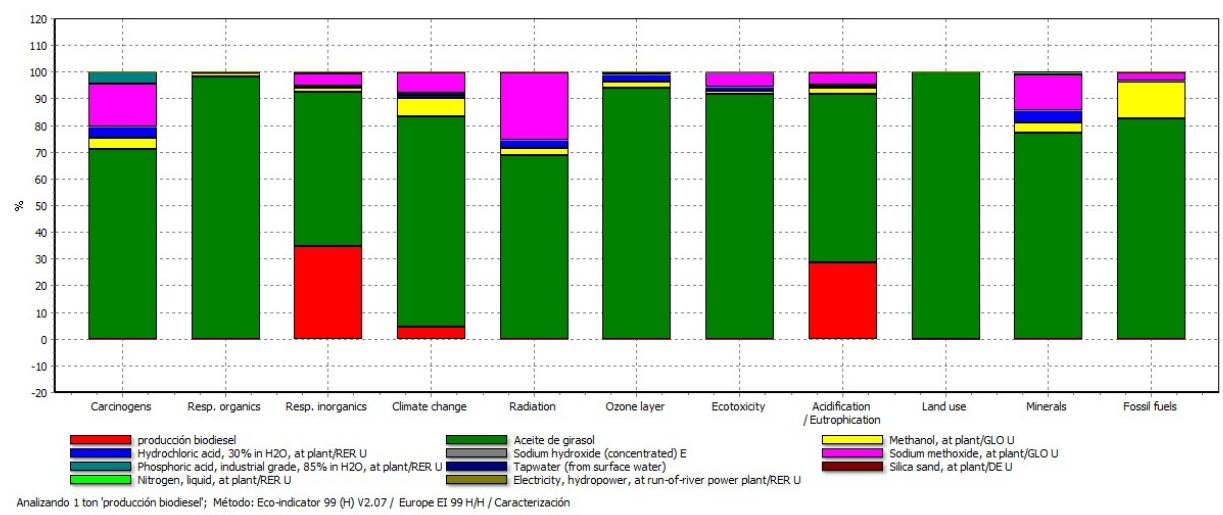

Figure 8. Results obtained from the description of impacts in the Life Cycle of Biodiesel.

Sunflower oil is the most relevant since it is present in all the impact categories, which indicates that the raw material is fundamental in all the soil, ecotoxicity and ozone layer impact cycles, among many others.

\subsection{Impact valuation using normalization and weighting}

Assessments were obtained by weighting and by unifying the characteristics in the protection areas. The most important areas were human health, with $40 \%$ of importance; the quality of the ecosystem, with $40 \%$, and $20 \%$ for the resources. The results are shown in the following figure:

The quality of the ecosystem is highlighted as the most affected area in the graph, and the sunflower oil, which is the raw material, is the most important factor. This can be observed in the three areas, but the human health and the resources are less affected. However, when dividing the same factors by a normal value (normalization), there are not significant differences between one and the other form of valuation.

In the implicit ranking of this classification, it is evident that the primary sector determines massive intervention processes and transformation of elements, and natural processes. The secondary sector, through its emissions, effluents and waste production, generates an impact that is, at first sight, less evident, but it may be more dangerous, for there are new factors which are dangerous for the human health or the environment. Finally, a big deal of the tertiary sector generate moderate impacts, with transport as the exception (Pérez, 2007). 


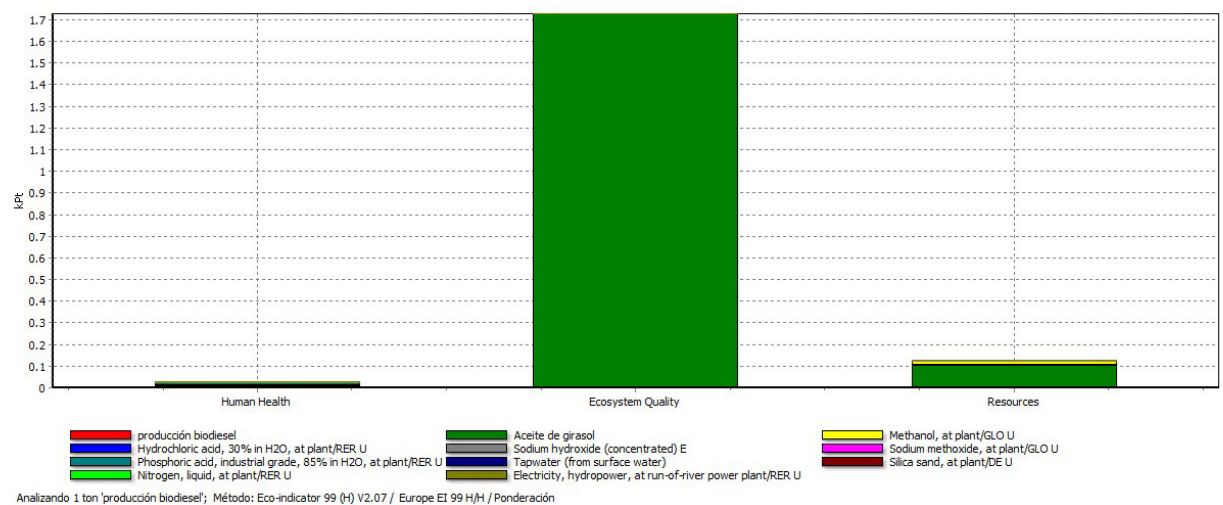

Figure 9. Results obtained from the assessment of impacts of the Life Cycle of Biodiesel (Weighting)

Both assessments show the contributions of the negative impact in the quality of the ecosystem mainly connected to soil erosion. Thus, the use of the land to be used for raw material production should be the first thing to take into account when implementing biodiesel. The seriousness of these impacts depends on the crops expansion and the environmental goods and services that provide the affected ecosystems (Blanco and Azqueta, 2007).

\subsection{Damage assessment}

Damage assessment results are shown in graph 26, and consist of the relative contribution of the stages of the Life Cycle in negative impacts on the environment and affect the three protection areas issued previously.

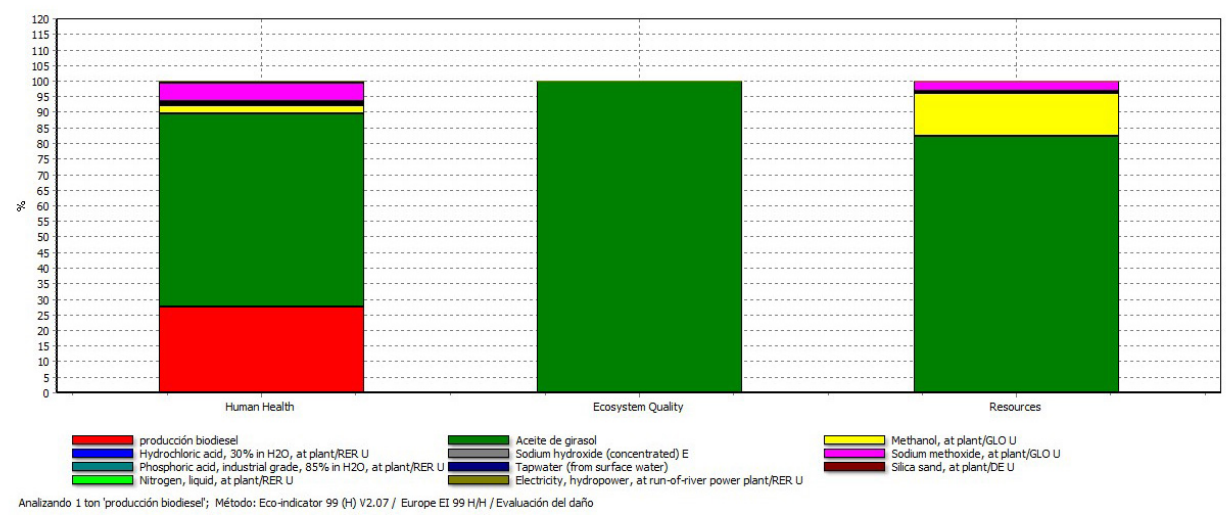

Figure 10. Environmental Damage Assessments in the Life Cycle of biodiesel. 
Sunflower oil (integrated in the agricultural phase) has a $100 \%$ effect in the quality of the ecosystem, a $60 \%$ effect in human health and a similar percentage in the use of resources. Most of the environmental negative impacts start in the agricultural production of the oil, linked to the intensive use of agrochemicals, soil erosion and overexploitation of the resources. Such situations are derived from specific local conditions and are therefore not general.

This may be due to the huge quantity of soil (natural resources) that is used to grow sunflowers and to the agricultural practices which include the use of pesticides that may affect the state of the environmental conditions of nearby ecosystems mainly in terms of biological quality; for the use of pesticides is linked to soil, water and biota pollution in bio-accumulation processes, and in high concentration it may provoke great damage in human health (Timmer, 2002).

\subsection{Singular rate}

A singular indicator of the impact of the Life Cycle was obtained when the description, weighting and year evaluation were integrated (figure 11). In this indicator there are two processes to be considered: sunflower oil and imported methanol.

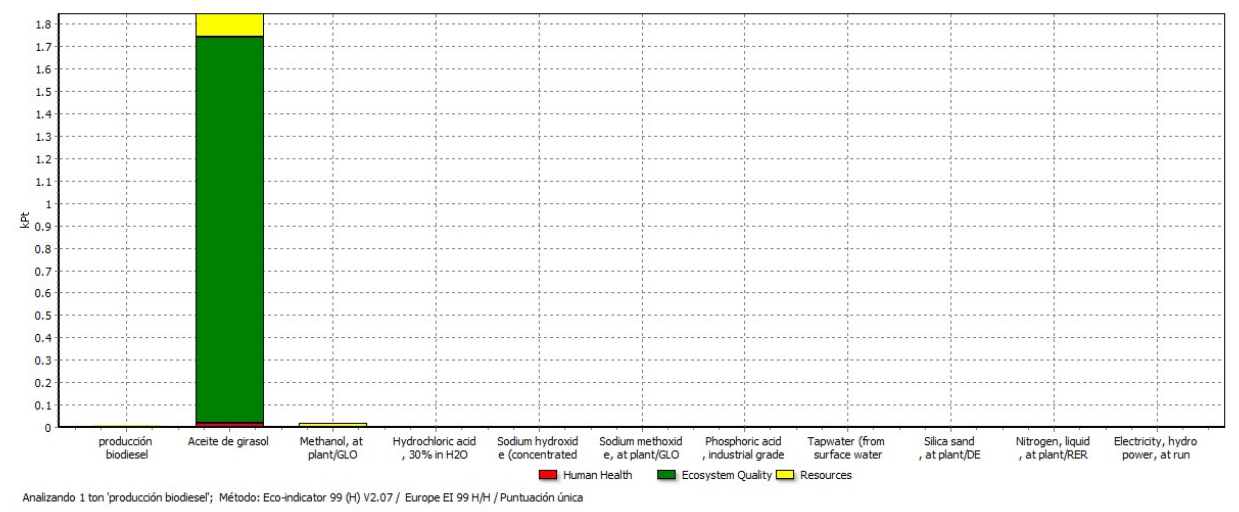

Figure 11. Indicator of the Life Cycle of Biodiesel.

The first one is highly relevant (EPA, 2002), because this would be the indicator of the Life Cycle in which almost all of the impacts affect, being the quality of the ecosystem the most affected protection area by the production and use of sunflower biodiesel in Paraguay.

\section{Conclusion}

The energy balance is positive; indicating that under the considerations made in this study, the energy system is efficient. This is due to the relationship between energy generated and 
consumed is greater than one, implying that the system meets the energy function. The environmental impacts evaluated in the biodiesel life cycle phase is related to agricultural ecosystem quality being the most affected area of protection. It affects $100 \%$ of the impact factors which influence the use of fossil fuels, pesticides and phosphate fertilizers. Besides the lack of treatment of discharges and waste in the industrial phase, high use of natural resources (land) is another important factor to consider but biofuels may represent a valid alternative energy if there are any mitigating impacts taking into account environmental considerations mentioned.

\section{Author details}

Estelvina Rodríguez Portillo ${ }^{1}$, José Ricardo Duarte Ojeda ${ }^{1}$ and Sully Ojeda de Duarte ${ }^{2}$

1 Universidad Autónoma del Estado de México. Toluca, Estado de México, México

2 Universidad Católica Nuestra Señora de la Asunción, Paraguay

\section{References}

[1] Rajagopal, D. y Zilberman, D.. Review of environmental, economic and policy aspects of biofuels.World. Bank Policy Research Working Paper No. 4341. Washington, DC, World Bank; 2007.

[2] Marchetti, J. et al. Possible methods for biodiesel production. Renewable and Sustainable Energy Reviews 11, 2007; 1300-1311.

[3] Donato, L. B. Estimación del consumo potencial de gasoil para las tareas agrícolas, transporte y secado de granos en el sector agropecuario, IX Congreso Argentino de Ingeniería Rural y I del MERCOSUR - CADIR 2007. Edited in CD. September 19 to $22 ; 2007$

[4] Anderson, K. and Valenzuela, E. The World Trade Organization's Doha Cotton Initiative: a tale of two issues. The World Economy, 2007; 30(8): 1281-1304.

[5] Ma, F. and Hanna M.A. Biodiesel production: a review. Bioresour Technol 1999;70:1-15.

[6] Harding, et al. A life - cycle comparison between inorganic ando biological catálisis for the production of biodiesel. Journal of Cleaner Production. Volume 16.- 3-2008; Pag. 1327-1436.

[7] Pérez C Análisis general de la cadena de valor del biodiesel en El Salvador, Servicio Holandés de Cooperación al Desarrollo SNV y el Consejo Empresarial Salvadoreño para el Desarrollo Sostenible (CEDES); 2007. 
[8] Blanco M and Azqueta D Can the Environmental Benefits of Biomass Support Agriculture? Energy Policy; 2007, Volume 36, Pag. 357-466

[9] Timmer, C.P.. Agriculture and economic development .En B.L. Gardner y G.C. Rausser, eds. Handbook of agricultural economics, Vol. 2A. Amsterdam, North-Holland; 2002.

[10] EPA, Environmental Protection Agency. A Comprehensive Analysis of Biodiesel Impacts on Exhaust Emissions. Draft Technical Report. United Status. 126 p.; 2002. 
